\title{
Air-condition Control System of Weaving Workshop Based on LabVIEW
}

\author{
Song Jian ${ }^{1,2}$, Wang Kai' ${ }^{2}$, Zhang Xiaochen ${ }^{2}$ \\ ${ }^{1}$ College of machinery, Weifang University, Weifang 261061,China; \\ ${ }^{2}$ Colege of Mechanical Engineering, Changzhou University,Changzhou ,213000, China
}

Keywords: Lab-VIEW; Data collection device; Temperature transmitter; Humidity sensor; Weaving workshop

\begin{abstract}
The project of air-condition measurement and control system based on LabVIEW is put forward for the sake of controlling effectively the environmental targets in the weaving workshop. In this project, which is based on the virtual instrument technology and in which LabVIEW development platform by NI is adopted, the system is constructed on the basis of the virtual instrument technology. It is composed of the upper PC, central control nodes based on CC2530, sensor nodes, sensor modules and executive device. Fuzzy control algorithm is employed to achieve the accuracy control of the temperature and humidity. A user-friendly man-machine interaction interface is designed with virtual instrument technology at the core of the software. It is shown by experiments that the measurement and control system can run stably and reliably and meet the functional requirements for controlling the weaving workshop.
\end{abstract}

\section{INTRODUCTION}

With the development of the textile industry, there are higher and higher demands for the environmental index of the weaving workshop, the key to which is the regulation of the temperature and humidity ${ }^{[1,2]}$. It is of great significance to maintain a certain temperature and humidity in accordance with different production varieties for the product quality, production rate and the labor intensity of the workers ${ }^{[3,4]}$.

LabVIEW, a virtual instrument platform developed by National Instrument(NI), is a development tool for creating applications using icon code instead of text programming language ${ }^{[5,6]}$. The data acquisition system designed with LabVIEW can simulate various signal acquisitions, and brings great convenience to the development of the measurement and control system ${ }^{[7,8]}$. In order to control effectively the weaving workshop environment, enhance the production and management process level and improve the product quality, in this paper, the air-condition measurement and control system for the weaving workshop is designed and developed, in which LabVIEW by NI is adopted as the software platform, with a hardware structure of PC plus Data Acquisition Card (DAQ), and virtual instrument technology is applied to the control of temperature and humidity in the weaving workshop.

\section{HARDWARE COMPONENTS}

The air-condition measurement and control system for the weaving workshop is a typical data acquisition system, whose hardware system employs virtual instrument system based on Data Acquisition Card (DAQ). The hardware structure block diagram is shown as in Fig.1. 


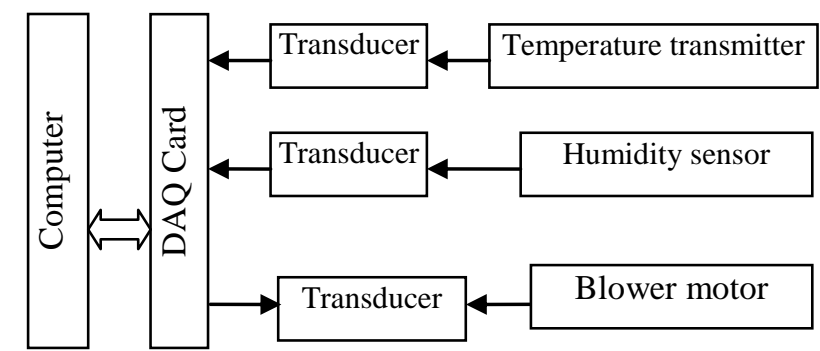

Fig.1 Block diagram of the hardware structure

\section{A. Data Acquisition Card (DAQ).}

Data Acquisition of the virtual instrument system based on LabVIEW is performed through the interfaced devices, whose main channel is via DAQ card. PCI-6023E card produced by NI is chosen as the DAQ card of this system for the sake of direct driving in LabVIEW environment.

PCI-6023E card is a 12-bit multi-channel data acquisition module, which integrates such functions as A/D conversion, D/A conversion and digital I/O. It has USB16 single-ended/USB8 differential analog input, whose sample range can be up to $200 \mathrm{KS} / \mathrm{s}$ and whose input range from \pm 0.05 to $\pm 10 \mathrm{~V}$, with eight $5 \mathrm{~V} / \mathrm{TTL}$ digital $\mathrm{I} / \mathrm{O}$ lines and two 24-bit timers/counters.

\section{B. Temperature Transmitter}

The LM335 series produced by NS are a kind of integrated temperature transmitter with highaccuracy and simple-adjustability, whose performance characteristics are analogous to Zener diode. The sensitivity of this device is $10 \mathrm{mV} / \mathrm{K}$, the dynamic impedance is less than $1 \Omega$, the current margin is from $400 \mu$ Ato $5 \mathrm{~mA}$, the accuracy is $1{ }^{\circ} \mathrm{C}$, and the temperature ranges from $-40^{\circ} \mathrm{C}$ to $+100^{\circ} \mathrm{C}$.

\section{Humidity Sensor}

For the $\mathrm{JCJ} 100 \mathrm{H} 1$ humidity sensor, the measurement range is from $0-100 \% \mathrm{RH}$, the accuracy $0.1 \% \mathrm{RH}$, and the fundamental error $\pm 0.2 \% \mathrm{~F}$.S. Because the humidity sensitive capacitor of highaccuracy is adopted in conjunction with the linear amplifying circuit and the temperaturecompensation circuit, it has such advantages as high sensitivity, better stability, high accuracy, reliable performance and long service life.

\section{Regulating Executive Device}

The regulating executive body of the system is the ventilation and humidity reducing devices driven by the electric motor controlled by the frequency converters. As the ventilation fan works under a long and continuous condition, which belongs to continuous constant load, there is no overload in normal circumstances. On view of the above two points, AC frequency conversion speed regulator for the tailored version of the fan is selected.

\section{Design of Fuzzy Controller}

Since the temperature and the humidity in the weaving workshop, which are much interfered by the external environment, is a time-varying nonlinear system with an uneven distribution of the physical quantity, it is difficult to build a precise math model and to reach a satisfying effect with the classic PID control. Furthermore, it requires more of the system economy but less of control time and tracking errors. It is suitable for fuzzy control, which possesses strong robustness, to be adopted in this high inertial nonlinear system as it is not requested to establish a math model for the controlled object. Therefore, fuzzy control algorithm is used to control the weaving workshop system.

The temperature and the humidity are served as the master control factor of fuzzy control. An output variable is obtained through fuzzification, fuzzy reasoning, and defuzzification to control the ventilation fan, thus achieving the goal off controlling the workshop environment. The fuzzy realtime control can be conducted by way of table look-up. Fig.2 is the flow chart of fuzzy control software. 


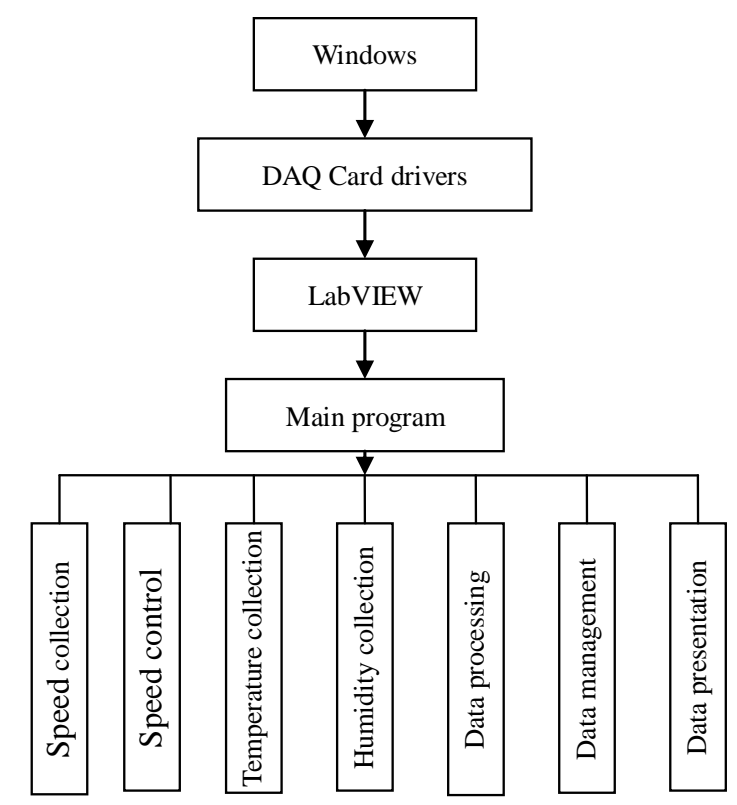

Fig.2 Flow chart of fuzzy control software

\section{Software Design}

When the hardware circuit is determined, the system software is programmed using LabVIEW, the virtual instrument development platform by NI. LabVIEW is a graphical programming language which is simple and intuitive and the most widely applied and most powerful virtual instrument development platform at present ${ }^{[9,10]}$.

\section{A. Overall Software Structure}

The software structure of the control system is shown as in Fig.3. The master control module takes charge of the system interface management, program flow control and the coordination and communication among the modules. The rotate speed control and acquisition module controls the fan motor rotate speed and collects the velocity sensor signals. The data processing and display module processes the acquired sensor signals and displays them on the front panel. The data management module performs the functions of data storage and playback, and report generation, etc.

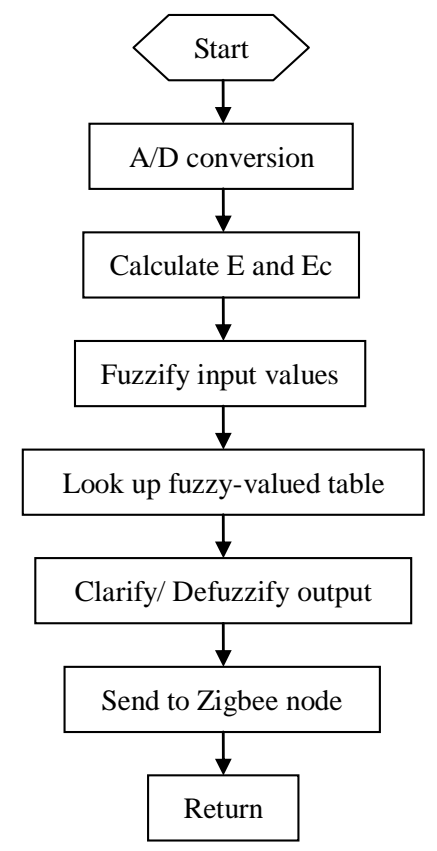

Fig. 3 Block diagram of the software structure 


\section{B. The Master Programs}

The master control module is at the management and control level and invokes other modules by means of event-driven. When the main program runs, firstly the temperature and humidity value are set up; and then "Detection Start" button is clicked; information of temperature and humidity is collected by the data acquisition module through multi-channels and processed by the data processing module; thus the driving frequency of the regulating fan is obtained.

\section{The Front Panel}

The front panel of control system consists of the display portion and the control portion. The display portion shows numerically the temperature, humidity and the rotate speed of the fan. The control portion can choose the temperature value and the humidity

\section{Conclusion}

Signal sensor technology, automatic control technology, computer hardware and software technology are comprehensively used in air-condition control system of the weaving workshop based on LabVIEW, and virtual instrument technology is applied to the measurement and control system. It not only achieves automatic test, but also improves the testing accuracy, expands test functions, shortens the system development cycle, and reduces hardware costs. It is demonstrated by the operational tests that the LabVIEW-based air-condition control system works stably and reliably, fully meeting the requirements of the weaving workshop.

\section{Acknowledgement}

This work is supported by Shandong Provincial Natural Science Foundation (No.Y2008G32) and Shandong Provincial universities Scientific Research Project (No.J09LG53).

\section{References}

[1] Z. R. Jin, Y. k. Han, J. Song, Intelligent Controlling System Based on CAN Bus for Textile Workshop, J. Journal of Weifang University, 43(20010) 56-57

[2] X.Y. Li, Discussion on energy saving design of textile air conditioning system, J. Shanghai Textile Science \& Technology, 45(2012) 102-105

[3] L.L. Dai. Air Conditioning System Design, Chemical Industry Press, Beijing, 2014

[4] Q. Luo, Worm gear reducer test-bed based on LabVIEW, J. Mechanical and Electrical Engingeering Magazine, 24(2007) 109-110

[5] J.F. Yang, P.F. Han, W.P. Bai, Design of smart torque sensor based on LabVIEW. Electronic Measurement Technology, 35(2011) 72-74

[6] L.L. Wang, H.Zhang, Computer measurement and control system for the pump based on LabVIEW, J.. Chinese Journal of Scientific Instrument, 28(2009) 230-232

[7] J. Saliga, L.Michaeli, Software for metrological characterisation of PC sound cards. Computer Standards \& Interfaces, J. 235(2013) 45-55

[8] C. Serodio, J.B. Cunha, R. Morais, A networked platform for agricultural management systems. Computers and Electronics in Agriculture, J. 41(2011) 75-90

[9] S.X. Chen. A Valuable Book of LabVIEW, Electronic Industry Press, Beijing, 2012

[10] J.A, Cai, Virtual instrument for design and control operation on the pipe - network of water supply, J. Anhui Gongye Daxue Xuebao, 30(2013) 23-27 